\section{BMJ Open Respiratory Research}

\title{
Ambient air pollution is associated with airway inflammation in older women: a nested cross-sectional analysis
}

\author{
Michael J Abramson (1) , ${ }^{1}$ Claudia Wigmann, ${ }^{2}$ Hicran Altug, ${ }^{2}$ \\ Tamara Schikowski (iD ${ }^{2}$
}

To cite: Abramson MJ, Wigmann $\mathrm{C}$, Altug $\mathrm{H}$, et al. Ambient air pollution is associated with airway inflammation in older women: a nested cross-sectional analysis. BMJ Open Resp Res 2020;7:e000549. doi:10.1136/ bmjresp-2019-000549

- Additional material is published online only. To view please visit the journal online (http://dx.doi.org/10.1136/ bmjresp-2019-000549)

Received 17 December 2019 Revised 2 March 2020 Accepted 3 March 2020
D) Check for updates

(c) Author(s) (or their employer(s)) 2020. Re-use permitted under CC BY-NC. No commercial re-use. See rights and permissions. Published by BMJ.

${ }^{1}$ School of Public Health and Preventive Medicine, Monash University, Melbourne, Victoria, Australia

${ }^{2}$ Environmental Epidemiology of Lung, Brain and Skin Aging Leibniz Research Institute for Environmental Medicine, Dusseldorf, NordrheinWestfalen, Germany

Correspondence to Dr Tamara Schikowski; Tamara.Schikowski@|UFDuesseldorf.de

\section{ABSTRACT}

Background Air pollution is a risk factor for chronic obstructive pulmonary disease (COPD). Fraction of exhaled nitric oxide (FeNO) could be a useful biomarker for health effects of air pollutants. However, there were limited data from older populations with higher prevalence of COPD and other inflammatory conditions.

Methods We obtained data from the German Study on the influence of Air pollution on Lung function, Inflammation and Ageing. Spirometry and FeNO were measured by standard techniques. Air pollutant exposures were estimated following the European Study of Cohorts for Air Pollution Effects protocols, and ozone $\left(\mathrm{O}_{3}\right)$ measured at the closest ground level monitoring station. Multiple linear regression models were fitted to FeNO with each pollutant separately and adjusted for potential confounders.

Results In 236 women (mean age 74.6 years), geometric mean FeNO was 15.2ppb. Almost a third $(\mathrm{n}=71,30.1 \%)$ of the women had some chronic inflammatory respiratory condition. A higher FeNO concentration was associated with exposures to fine particles $\left(\mathrm{PM}_{2.5}\right), \mathrm{PM}_{2.5 \text { absorbance }}$ and respirable particles $\left(\mathrm{PM}_{10}\right)$. There were no significant associations with $\mathrm{PM}_{\text {coarse }}, \mathrm{NO}_{2}, \mathrm{NO}_{x}, \mathrm{O}_{3}$ or length of major roads within a $1 \mathrm{~km}$ buffer. Restricting the analysis to participants with a chronic inflammatory respiratory condition, with or without impaired lung function produced similar findings. Adjusting for diabetes did not materially alter the findings. There were no significant interactions between individual pollutants and asthma or current smoking.

Conclusions This study adds to the evidence to reduce ambient $\mathrm{PM}_{2.5}$ concentrations as low as possible to protect the health of the general population.

\section{INTRODUCTION}

Air pollution is responsible for a substantial burden of mortality and morbidity in countries such as India and China with very high ambient concentrations of fine particles $<2.5 \mu \mathrm{m}$ diameter $\left(\mathrm{PM}_{2.5}\right){ }^{1}{ }^{2}$ However, there does not appear to be a threshold below which adverse health effects of $\mathbf{P M}_{2.5}$ are not observed. The UK Biobank study of over 300000 individuals reported that much lower modelled concentrations of $\mathrm{PM}_{2.5}$, as well as respirable particles $<10 \mu \mathrm{m}$ diameter $\left(\mathrm{PM}_{10}\right)$

\section{Key messages}

What is the key question?

- Is low level ambient air pollution associated with airway inflammation?

\section{What is the bottom line?}

- Exposure to fine airborne particles $\left(\mathrm{PM}_{25}\right)$ was associated with airway inflammation, as detected by the fraction of exhaled nitric oxide in this sample of 236 older women in Germany, almost a third of whom had some chronic inflammatory respiratory condition.

\section{Why read on?}

- These findings suggest that $\mathrm{PM}_{2.5}$ concentrations need to be reduced as low as possible to protect the health of the general population.

and nitrogen dioxide $\left(\mathrm{NO}_{2}\right)$ were associated with the prevalence of chronic obstructive pulmonary disease (COPD). ${ }^{3}$

Since 1990, COPD has overtaken tuberculosis and become the seventh leading cause of mortality in the 2017 Global Burden of Disease study. ${ }^{4}$ COPD is also a highly prevalent condition in many countries with ageing populations, for example $7.5 \%$ of Australian adults over the age of 40 , and $29.2 \%$ of those over the age of 75 years met criteria for the Global initiative for Obstructive Lung Disease (GOLD) definition of COPD Stage two or greater. $^{5}$ Within Europe, the prevalence of COPD of this severity in adults over 40 years old ranged from $5.9 \%$ in Hannover, $8.3 \%$ in Bergen and $10.6 \%$ in Salzburg to $10.9 \%$ in Krakow. ${ }^{6}$ The major known and preventable cause of COPD is active smoking of tobacco. ${ }^{6}$ However, many other causes have been identified, including genetic disorders such as $\alpha_{1}$ antitrypsin deficiency, occupational exposures $^{7}$ and air pollution.

Airway inflammation is one of the potential pathophysiological mechanisms by which air pollutants can affect respiratory health in 
both children and adults. The fraction of exhaled nitric oxide $(\mathrm{FeNO})$ is a well-validated non-invasive marker of airway inflammation, particularly eosinophilic inflammation. It has long been known that children ${ }^{8}$ and adults with poorly controlled asthma have elevated FeNO levels and that these levels can be reduced by inhaled corticosteroids. ${ }^{9}$ The American Thoracic Society (ATS) has developed guidelines for the measurement of FeNO in clinical practice. ${ }^{10}$ More recently, it has been proposed that $\mathrm{FeNO}$ could also be a useful biomarker to detect airway inflammation as an effect of exposure to air pollution. ${ }^{11}$ However, there were limited FeNO data from older populations with higher prevalences of COPD and other chronic inflammatory conditions.

The aim of this study was to investigate whether exposures to particulate matter, oxides of nitrogen and ozone were related to $\mathrm{FeNO}$ in a cohort of older women.

\section{METHODS}

The data were obtained from the Study on the influence of Air pollution on Lung function, Inflammation and Ageing. Details of this female cohort from the Ruhr area and Southern Münsterland of Germany have been described elsewhere. ${ }^{12}$ Baseline examinations of 4874 women aged 54-55 years were undertaken between 1985 and 1994. This analysis presents selected symptom and lung function data from the second follow-up of 834 women, which was conducted in $2007-2010 .^{13}$ The Medical Ethics Committees of the Ruhr University, Bochum and Heinrich-Heine University, Düsseldorf approved the examinations and all participants provided written informed consent.

Spirometry was performed following guidelines of the ATS and European Respiratory Society (ERS). ${ }^{14}$ Measurements included the forced expiratory volume in $1 \mathrm{~s}\left(\mathrm{FEV}_{1}\right)$, forced vital capacity (FVC) and the ratio of $\mathrm{FEV}_{1} / \mathrm{FVC}$ was calculated. To account for effects of age, sex and height, $\mathrm{z}$ scores were estimated using the Global Lung Initiative (GLI) reference set, ${ }^{15}$ which fitted our data well. ${ }^{13}$ The lower limit of normal (LLN) was defined as $\mathrm{z}<-1.28$ (lower $10 \% \mathrm{le}$ ). $\mathrm{FeNO}$ was measured in 196 women with a NIOX Flex (formerly manufactured by Aerocrine, Solna, Sweden) and 40 with CLD 78 TR (Ecomedics AG, Dürnten, Switzerland) equipment during exhalation at $50 \mathrm{~mL} / \mathrm{s}$, following recommendations of the ATS. ${ }^{16}$ Participants attended the laboratory fasting, were asked not to smoke and not tested until after recovery from a respiratory tract infection.

Exposure to air pollution was assessed by land-use regression (LUR) models following the European Study of Cohorts for Air Pollution Effects (ESCAPE) protocols. ${ }^{17}{ }^{18}$ Exposure concentrations were estimated using the ESCAPE LUR model (which was for 2008-2009) at the home residential addresses on follow-up (2007-2010). These were forward extrapolated by the ratio method, if the participant was examined after 2008-2009, and back extrapolated by the ratio method, if the participant was examined before 2008-2009. The length of major roads (>5000 vehicles/day) within a $1 \mathrm{~km}$ buffer of the home address was also estimated for the ESCAPE project using digital road network linked with traffic intensity data in a Geographic Information System. The 5-year (2004-2008) mean concentration of daily maximum rolling 8-hour mean ozone at the home address was measured at the closest monitoring station (Landesamt für Natur, Umwelt und Verbraucherschutz, NRW).

\section{Statistical methods}

We used natural log-transformed FeNO values because of the right-skewed distribution (online supplementary figure S1). Multiple linear regression models were fitted to $\log _{\mathrm{e}} \mathrm{FeNO}$ with each pollutant separately. These models adjusted for potential confounders ${ }^{19}$ such as age, height, weight, current smoking, former smoking, secondhand smoke (SHS) exposure, urban/rural residence, socioeconomic status (SES; defined as highest education of the participant or her spouse; low $<10$ years, medium $=10$ years, high: $>10$ years of education) and which equipment was used to make FeNO measurements. Two missing values for SES and one missing value for SHS were replaced by the most frequently observed value ('medium' for SES, 'yes' for SHS).

We performed additional sensitivity analyses by restricting the analyses to women with chronic inflammatory respiratory conditions (asthma, chronic bronchitis, hayfever, cough, cough with sputum or COPD), as well as to those with chronic inflammatory respiratory conditions or lung function below the LLN. Chronic bronchitis was defined as cough and sputum for $\geq 3$ months on $\geq 2$ years. We investigated potential effect modification by asthma and smoking status using appropriate interaction terms. We also compared our results with models that additionally adjusted for diabetes. Results were expressed as proportional changes per interquartile range (IQR) of the pollutant and $95 \%$ CI. All analyses were conducted in R, V.3.6.0 (20).

\section{Patient and public involvement}

As this was an epidemiological study, there were no patients. It was not appropriate or possible to involve the public in the design, or conduct, or reporting, or dissemination plans of our research.

\section{RESULTS}

\section{Description of participants and exposures}

Characteristics including lung function of participants are described in table 1 . On average, the women were 74.6 years old and moderately overweight (mean body mass index $\left.27.6 \mathrm{~kg} / \mathrm{m}^{2}\right)$. Of the 236 women, $137(58.1 \%$ ) came from an urban area and $99(41.9 \%)$ from a rural area. Most of the women had medium or high SES (low: 17.0\%, medium: $48.7 \%$, high: $34.3 \%$ ). Spirometry was close to what would have been predicted in a sample of women 


\begin{tabular}{|c|c|c|c|c|}
\hline & Mean & SD & Minimum & Maximum \\
\hline Age (years) & 74.6 & 2.6 & 70.1 & 79.1 \\
\hline Height (cm) & 162 & 6.0 & 138 & 178 \\
\hline Weight (kg) & 72.8 & 13.6 & 41 & 132 \\
\hline $\mathrm{BMI}\left(\mathrm{kg} / \mathrm{m}^{2}\right)^{\prime}$ & 27.6 & 4.75 & 17.1 & 45.7 \\
\hline $\mathrm{FEV}_{1}$ z score & 0.03 & 1.07 & -2.75 & 2.71 \\
\hline FVC z score & 0.16 & 0.90 & -3.15 & 2.26 \\
\hline $\begin{array}{l}\text { FEV }_{1} / \text { FVC z } \\
\text { score }\end{array}$ & -0.33 & 0.83 & -3.38 & 1.45 \\
\hline FeNO/ppb & 19.1 & 16.1 & 1.90 & 128 \\
\hline $\log _{e} \mathrm{FeNO}$ & 2.72 & 0.66 & 0.64 & 4.85 \\
\hline
\end{tabular}

SD: Standard deviation

BMI, body mass index; FeNO, fraction of exhaled nitric oxide;

$\mathrm{FEV}_{1}$, forced expiratory volume in $1 \mathrm{~s}$; FVC, forced vital capacity.

of this age. $\mathrm{FEV}_{1}$ was below LLN in $28(11.9 \%)$, FVC in $12(5.1 \%)$, the $\mathrm{FEV}_{1} / \mathrm{FVC}$ ratio in $28(11.9 \%)$ and any of these spirometric indices in $45(19.1 \%)$ participants. Demographic characteristics and lung function were similar to the other 598 women seen at this follow-up who did not have FeNO measurements (data not shown). The distributions of $\mathrm{FeNO}$ and $\log _{\mathrm{e}} \mathrm{FeNO}$ (referred to simply as FeNO hereafter) are shown in online supplementary figure S1. Geometric mean (geometric SD) FeNO was 15.2 (1.93) ppb. The majority of measurements (81.4\%) fell within the low range ( $<25 \mathrm{ppb}), 13.6 \%$ were moderate $(25-50 \mathrm{ppb})$ and $5.1 \%$ high ( $>50 \mathrm{ppb})$, as proposed by the ATS. $^{10}$

There were $11(4.7 \%)$ current smokers, 41 (17.4\%) former smokers and 127 (53.8\%) had been exposed to SHS. The prevalences of chronic respiratory and other conditions and symptoms are shown in table 2. The most common self-reported symptom was cough. Around one in ten participants reported ever having asthma, symptoms of chronic bronchitis or hayfever. Almost a third $(n=71)$ reported any of the above chronic inflammatory respiratory conditions and sensitivity analysis focused on

Table 2 Prevalences of chronic respiratory and other conditions and symptoms $(n=236)$

\begin{tabular}{lll}
\hline & Yes & Missing \\
\hline Asthma ever & $23(9.7 \%)$ & $0(0 \%)$ \\
Current asthma & $16(6.8 \%)$ & $3(1.3 \%)$ \\
Chronic bronchitis & $23(9.7 \%)$ & $2(0.8 \%)$ \\
Hayfever & $24(10.2 \%)$ & $0(0 \%)$ \\
Cough & $31(13.1 \%)$ & $6(2.5 \%)$ \\
Cough with sputum & $10(4.2 \%)$ & $8(3.4 \%)$ \\
$\begin{array}{l}\text { Chronic obstructive } \\
\text { pulmonary disease }\end{array}$ & $6(2.5 \%)$ & $0(0 \%)$ \\
Any respiratory condition & $71(30.1 \%)$ & $0(0 \%)$ \\
Diabetes & $19(8.1 \%)$ & $1(0.4 \%)$ \\
\hline
\end{tabular}

this group (below). Having diabetes was reported by 19 $(8.1 \%)$ participants.

Individually assigned air pollutant concentrations are described in table 3 . The long-term mean concentrations of $\mathrm{PM}_{10}$ and $\mathrm{PM}_{2.5}$ in this sample of women exceeded the $\mathrm{WHO}$ annual air quality guidelines ${ }^{20}$ of 20 and $10 \mu \mathrm{g} / \mathrm{m}^{3}$, respectively. The $\mathrm{NO}_{2}$ concentrations were mostly below the WHO annual guideline of $40 \mu \mathrm{g} / \mathrm{m}^{3}$. The $\mathrm{O}_{3}$ concentrations fell within a narrow range and were all well below the WHO guideline for an 8 hour daily maximum of $100 \mu \mathrm{g} / \mathrm{m}^{3}$.

\section{Associations between air pollutants and FeNO}

The proportional changes in FeNO and 95\% CIs for an IQR in oxides of nitrogen, particulate matter or length of major roads within a $1 \mathrm{~km}$ buffer with FeNO for the fully adjusted models are shown in figure 1 . In all participants tested, the proportional change in FeNO associated with an IQR change in $\mathrm{PM}_{25}$ was 1.20 (95\% CI 1.04 to 1.39), $\mathrm{PM}_{2.5 \text { absorbance }} 1.10$ (95\% CI 1.01 to 1.20 ) and $\mathrm{PM}_{10} 1.13$ (95\% CI 1.01 to 1.26 ). There were no significant associations with $\mathrm{PM}_{\text {coarse }}, \mathrm{NO}_{2}, \mathrm{NO}_{\mathrm{x}}$, length of major roads or $\mathrm{O}_{3}$ (online supplementary table S1). Diabetes was associated with slightly lower FeNO levels, but fitting diabetes to the models did not materially alter the findings. There were no significant interactions between individual pollutants and asthma or current smoking (data not shown).

Restricting the analysis to the 71 participants with a chronic inflammatory respiratory condition produced similar findings (figure 1). There remained strong positive associations between FeNO and $\mathrm{PM}_{2.5}(1.68 ; 95 \%$ CI 1.24 to 2.26 ) and $\mathrm{PM}_{10}$ (1.32; 95\% CI 1.04 to 1.68$)$, but not $\mathrm{PM}_{2.5 \text { absorbance }}$. There were no significant associations with $\mathrm{PM}_{\text {coarse }}, \mathrm{NO}_{2}, \mathrm{NO}_{\mathrm{x}}$, length of major roads or $\mathrm{O}_{3}$ (online supplementary table S2). Fitting diabetes to the models did not materially alter the findings. There were no significant interactions between individual pollutants and current smoking (data not shown).

Finally, the analysis was restricted to 99 participants with either a chronic inflammatory respiratory condition or lung function below LLN. These findings are also presented in figure 1 . There were still strong positive associations between FeNO and $\mathrm{PM}_{25}(1.46 ; 95 \%$ CI 1.14 to 1.86$)$, as well as $\mathrm{PM}_{10}(1.26 ; 95 \% \mathrm{CI} 1.05$ to 1.52$)$ and $\mathrm{PM}_{2.5 a b s o r b a n c e}(1.18 ; 95 \% \mathrm{CI} 1.02$ to 1.37$)$. However, there were no significant associations with $\mathrm{PM}_{\text {coarse }}, \mathrm{NO}_{2}, \mathrm{NO}_{\mathrm{x}}$, length of major roads or $\mathrm{O}_{3}$ (online supplementary table S3). Fitting diabetes to the models did not materially alter the findings. There were again no significant interactions between individual pollutants and current smoking (data not shown).

\section{DISCUSSION}

This cross-sectional analysis nested within a cohort of ageing women from Germany showed that airway inflammation was consistently associated with moderate longterm exposures to fine airborne particles. There were 


\begin{tabular}{llllll}
\hline \multicolumn{5}{l}{ Table 3} & Description of individually assigned air pollution exposures at the follow-up $(2007-2010)$ of the cohort $(\mathrm{n}=236)$ \\
\hline $\mathrm{NO}_{2}$ & Mean & SD & IQR & Minimum & Maximum \\
\hline $\mathrm{NO}_{\text {x }}$ & 27.2 & 6.88 & 7.65 & 18.4 & 68.2 \\
$\mathrm{PM}_{10}$ & 44.1 & 17.3 & 19.4 & 21.7 & 115 \\
$\mathrm{PM}_{\text {coarse }}$ & 26.9 & 1.93 & 2.03 & 23.5 & 33.2 \\
$\mathrm{PM}_{2.5}$ & 9.56 & 1.53 & 1.68 & 4.40 & 14.7 \\
$\mathrm{PM}_{2.5 \text { absorbance }}$ & 17.5 & 1.45 & 2.11 & 14.2 & 21.4 \\
Major road length $<1 \mathrm{~km}$ buffer $_{\mathrm{O}_{3}}$ & 1.45 & 0.43 & 0.39 & 0.87 & 3.95 \\
\hline
\end{tabular}

IQR: Intrequartile Range SD: Standard deviation

$\mathrm{NO}_{2}$, nitrogen dioxide $\left(\mu \mathrm{g} / \mathrm{m}^{3}\right) ; \mathrm{NO}_{x}$, oxides of nitrogen $\left(\mu \mathrm{g} / \mathrm{m}^{3}\right) ; \mathrm{O}_{3}$, ozone $\left(\mu \mathrm{g} / \mathrm{m}^{3}\right) ; \mathrm{PM}_{10}$, particulate Matter $<10 \mu \mathrm{m}$ diameter $\left(\mu \mathrm{g} / \mathrm{m}^{3}\right) ; \mathrm{PM} \mathrm{M}_{2.5}$, particulate matter $<2.5 \mu \mathrm{m}$ diameter $\left(\mu \mathrm{g} / \mathrm{m}^{3}\right) ; \mathrm{PM}_{2}$ of $\mathrm{PM}_{10}$ calculated as $\mathrm{PM}_{10}$ minus $\mathrm{PM}_{2.5}\left(\mu \mathrm{g} / \mathrm{m}^{3}\right)$.

also associations with $\mathrm{PM}_{2.5 a b s o r b a n c e}$ and $\mathrm{PM}_{10}$, but no significant associations with $\mathrm{PM}_{\text {coarse }}, \mathrm{NO}_{2}, \mathrm{NO}_{\mathrm{x}}, \mathrm{O}_{3}$ or length of major roads within a $1 \mathrm{~km}$ buffer. The findings were similar in subgroups with chronic inflammatory respiratory conditions, with or without impaired lung function. Although diabetes is also a chronic inflammatory condition, fitting it to the models did not materially alter the findings. Nor were there any significant interactions between air pollutants and asthma or current smoking. The geometric mean FeNO was similar to that recently reported in healthy middle aged European women. ${ }^{19}$
To our knowledge, this is the first epidemiological study to examine FeNO as a biomarker of respiratory effects in older women exposed to relatively low concentrations of air pollutants, at least compared with WHO air quality guidelines. ${ }^{20}$ There have been some previous clinical studies in small panels of patients with COPD. Wu et al repeatedly measured $\mathrm{FeNO}$ in 23 patients with stable COPD who were exposed to very high concentrations of $\mathrm{PM}_{2.5}$ (median $97 \mu \mathrm{g} / \mathrm{m}^{3}$ ), $\mathrm{PM}_{10}, \mathrm{SO}_{2}$ and $\mathrm{NO}_{2}$ in Beijing. ${ }^{21}$ They found that an IQR increase in 5-day moving average $\mathrm{PM}_{2.5}$ was associated with a $21.9 \%$ increase in FeNO.

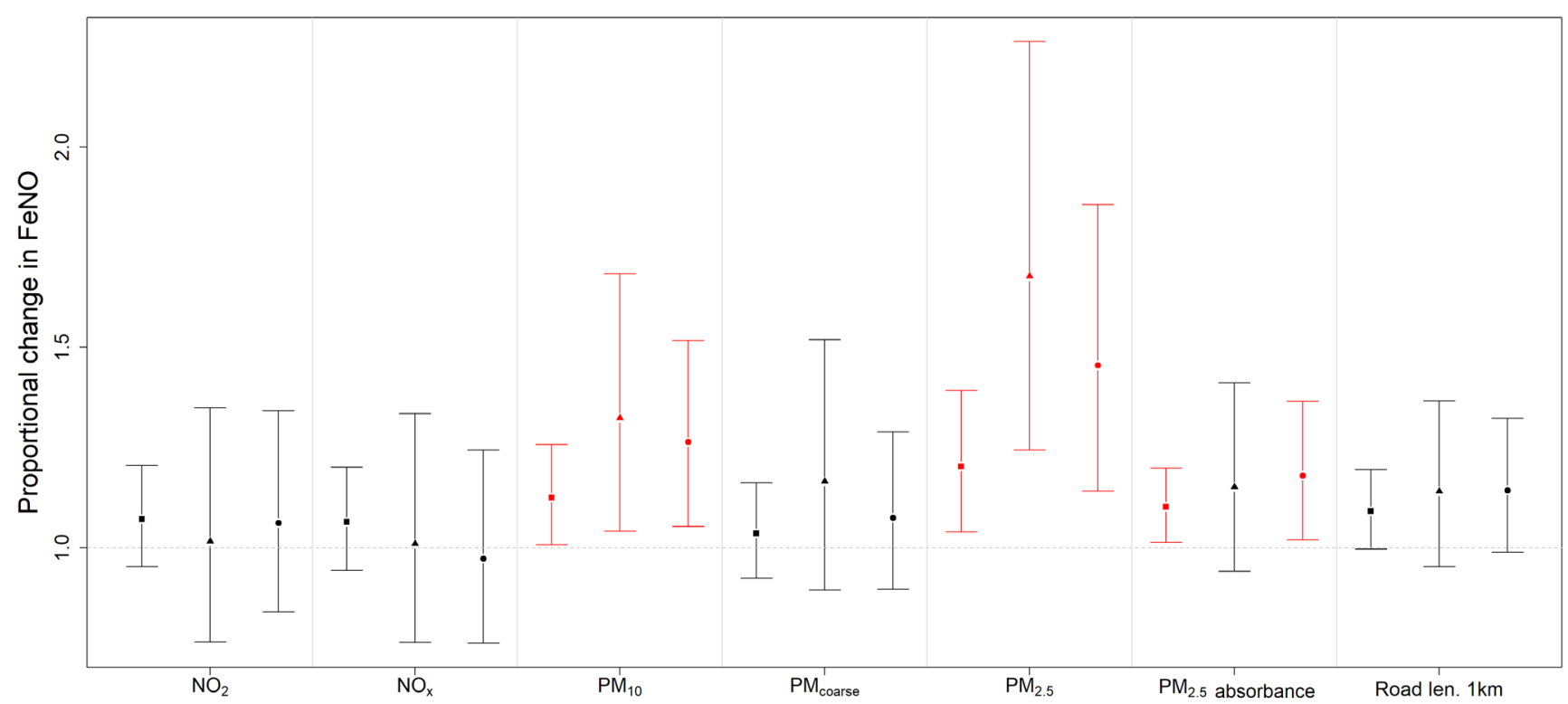

Figure 1 Proportional changes (and 95\% Cls) in FeNO for an IQR in oxides of nitrogen, particulate matter or major road length<1 km buffer in: all participants $(n=236), \Delta$ participants with chronic inflammatory respiratory conditions $(n=71)$ and - participants with chronic inflammatory respiratory conditions or lung function below the lower limit of normal ( $\mathrm{n}=99$ ). significant associations are indicated in red. estimates were adjusted for age, height, weight, current and former smoking, SHS exposure, urban/rural residence, SES and the FeNO measuring equipment. FeNO, fraction of exhaled nitric oxide; SES, socioeconomic status; SHS, secondhand smoke. 
However, there were no significant associations between $\mathrm{PM}_{10}, \mathrm{SO}_{2}$ or $\mathrm{NO}_{2}$ and $\mathrm{FeNO}$. Another panel study of 43 patients with stable COPD by the same investigators focused on $\mathrm{O}_{3}$ metrics in Beijing. ${ }^{22}$ Although 8-hour maximum $\mathrm{O}_{3}$ concentrations were associated with lung function $\left(\mathrm{FEV}_{1}\right)$, there was no significant association with FeNO. These findings for $\mathrm{PM}_{2.5}$ and $\mathrm{O}_{3}$ are consistent with ours.

There have been several previous cross-sectional studies of traffic-related air pollution and FeNO in children and adolescents, with or without asthma. A Canadian study of 9- to 11-year-old children found that roadways within $200 \mathrm{~m}$ of the home were associated with FeNO. ${ }^{23}$ However, another Canadian study of elementary school children did not find any relationship between measures of traffic volume and FeNO. ${ }^{24}$ The Children's Health Study measured FeNO in over 2000 school children from 13 communities in Southern California. ${ }^{25}$ The length of roads within $100 \mathrm{~m}$ of the home $\mathrm{e}^{26}$ and daily cumulative average $\mathrm{PM}_{2.5}, \mathrm{PM}_{10}$ and $\mathrm{O}_{3}$ were associated with higher FeNO levels, particularly in the warm season. ${ }^{25}$ We found an effect of $\mathrm{PM}_{2.5}$ as in the Children's Health Study, ${ }^{25}$ but the concentrations of $\mathrm{NO}_{2}$ and $\mathrm{O}_{3}$ were much higher in Southern California than in Germany. The Australian Child Health and Air Pollution study (ACHAPS) recruited from 12 cities 2630 children aged 7-11 years, of whom $14.9 \%$ had current asthma. ${ }^{27}$ An IQR increase in $\mathrm{NO}_{2}$ was associated with current asthma, decreased lung function $\left(\mathrm{FEV}_{1}, \mathrm{FVC}\right)$ and a $71 \%$ increase in FeNO. However, the mean $\mathrm{NO}_{2}$ exposure in ACHAPS $^{26}$ was similar to our participants, so perhaps children particularly those with asthma are more susceptible to inflammatory effects. Eckel et al measured FeNO in 1635 adolescents aged 12-15 years from Southern California. ${ }^{28}$ They found that indoor $\mathrm{NO}$ as a marker of traffic-related air pollutants was associated with several $\mathrm{FeNO}$ indices, consistent with an effect on the distal airways.

There have also been a few adult air pollution studies that have examined FeNO. A small controlled experimental study of 20 non-smoking atopic volunteers found no effects of wood smoke (200 or $400 \mu \mathrm{g} / \mathrm{m}^{3}$ ) on lung function, FeNO or nasal lavage. ${ }^{29}$ Mirabelli $e t$ al conducted a panel study of 39 adults with or without self-reported asthma exposed to traffic-related air pollutants during rush hour commuting in Atlanta. ${ }^{30}$ The largest post-commute increases in FeNO were observed in participants with below median asthma control. There was also an association between $\mathrm{PM}_{25}$ in the vehicle and $\mathrm{FEV}_{1}$ in this group. The $\mathrm{PM}_{2.5}$ concentrations inside vehicles in Atlanta ${ }^{30}$ were higher than those we estimated in ambient air. Again, this panel study highlighted the greater susceptibility of patients with current asthma, which was only present in $7 \%$ of our participants.

Responses in cardiorespiratory biomarkers to changes in air quality around the Beijing Olympic games were studied in healthy young adults aged 19-33 years by Zhang $e t a l .^{31}$ The mean concentrations of all air pollutants except $\mathrm{O}_{3}$ improved during the games, for example,
$\mathrm{NO}_{2}$ fell by $43 \%$ and $\mathrm{PM}_{2.5}$ by $27 \%$. This was associated with reductions in many inflammatory markers including a $60 \%$ fall in FeNO. Following the games, air quality deteriorated again accompanied by increases in inflammatory markers, including a $130 \%$ increase in FeNO. In Sweden, Modig et al measured FeNO at two flow rates in 5841 adults aged $25-75$ years. ${ }^{32}$ Ozone was associated with distal airway inflammation, but there was only a small effect of $\mathrm{NO}_{\mathrm{x}}$ and no clear effect of $\mathrm{PM}_{10}$. Although $\mathrm{PM}_{2.5}$ was not reported, exposures in this Swedish study ${ }^{32}$ were fairly similar to ours, so it is unclear why the main effect on FeNO was from $\mathrm{O}_{3}$. This study focused on shortterm exposures up to 120 hours, so perhaps the effects of $\mathrm{O}_{3}$ were reversible over longer periods.

People with diabetes are also more susceptible to the effects of air pollution. ${ }^{33}$ Peng et al conducted a panel study of 69 Boston residents with type 2 diabetes, in whom they made repeated measurements of FeNO. ${ }^{34}$ Interquartile increases in 6-hour averages of black carbon and particle number were associated with FeNO. There were also significant associations with 24 hours averages of black carbon and $\mathrm{NO}_{\mathrm{x}}$. We found an association with $\mathrm{PM}_{2.5 a b s o r b a n c e}$ which is a surrogate for black carbon in the whole group that persisted after fitting diabetes to the models. Unfortunately, we did not have measurements of ultrafine particles at the time of the follow-up investigation.

There is quite good biological plausibility that $\mathrm{PM}_{2.5}$ could induce airway inflammation via oxidative stress. Numerous experimental studies in rats and mice and some human panel studies have investigated the underlying pathophysiological mechanisms. ${ }^{35}$ As an example, one relevant animal study involved intratracheal installation of urban background $\mathrm{PM}_{2.5}$ in spontaneously hypertensive rats. ${ }^{36}$ This exposure triggered pulmonary inflammation, disturbed the pulmonary vasculature and provoked systemic inflammation. Many of the effects observed appear to involve disruption of redox signalling and induction of an immune response by reactive oxygen species, ${ }^{35}$ which include superoxide, hydroxyl radicals, $\mathrm{NO}$ and peroxynitrite. Protective proteins including pulmonary surfactant and antioxidants also play an important role that has become a target for interventions.

\section{Strengths and limitations}

The strengths of our study included the well-characterised cohort of the women. Lung function was measured following ATS/ERS guidelines and the most recent international reference set (GLI) applied to adjust for effects of age, sex and height. FeNO was measured in a subgroup using validated methods with careful attention to preparation and quality control. Air pollutant exposures were estimated following the standardised ESCAPE protocols for $\mathrm{PM}$ and $\mathrm{NO}_{\mathrm{x}}$ or local ground level measurements for $\mathrm{O}_{3}$. The data were fairly complete with only small numbers of missing values. Regression models were fitted to control for known potential confounders. 
However, there were also some limitations. Like any longitudinal study, there has been some attrition by the time this follow-up was conducted. Because this was a cross-sectional analysis, we need to be cautious about causal inference. We did not have access to data on medications, such as inhaled corticosteroids. Two different FeNO devices were used, which was allowed for by fitting the equipment to the regression models. There is some evidence for equivalence of $\mathrm{FeNO}$ measurements between these types of devices. ${ }^{37} \mathrm{FeNO}$ was only measured at one flow rate, so we could not partition between proximal and distal airway effects. Because exposure was only assessed at residential addresses, there might be some misclassification. However, the effect of non-differential misclassification of exposure would be to bias estimates towards the null. There were smaller numbers of participants with chronic inflammatory conditions or impaired lung function. Nonetheless the effects of $\mathrm{PM}_{2.5}$ were consistent in these subgroups. As in any epidemiological study, we accept the possibility of some residual confounding.

\section{CONCLUSION}

Our findings confirm an effect of long-term exposures to fine particles on airway inflammation in ageing women. Clearly further research is required in high-risk populations including those with asthma, COPD and other chronic inflammatory conditions including diabetes. However, we consider that there is already sufficient evidence to reduce recommended ambient $\mathrm{PM}_{2.5}$ concentrations as low as possible to protect the health of the general population. Physicians should continue to advise their elderly patients with chronic diseases to avoid strenuous exercise outdoors on days with reduced visibility from particulate pollution.

Acknowledgements We thank all study members and staff involved in data collection and also the respective funding bodies for SALIA. Study directorate: $\mathrm{R}$ Dolgner; U Krämer, U Ranft, T Schikowski, A Vierkötter. Scientific Team Baseline: AW Schlipköter, MS Islam; A Brockhaus, H Idel, R Stiller-Winkler, W Hadnagy, T Eikmann, Scientific Team Follow-up: D Sugiri, A Hüls, B Pesch, A Hartwig, H Käfferlein, V Harth, T Brüning, T Weiss. Study Nurses: G Seitner-Sorge, V Jäger, G Petczelies, I Podolski, T Hering, M Goseberg. Administrative Team: B Schulten, S Stolz. During the last decades, many scientists, study nurses and laboratories were involved in conducting the study. We are most grateful for all the women from the Ruhr area and Borken who participated in the study over decades and the local health Departments for organising the study.

Contributors MJA wrote the first draft of this manuscript. CW conducted statistical analysis of the data and produced the figures. All authors have made substantial contributions to the conception or design of the work; or the acquisition, analysis, or interpretation of data for the work; and drafting the work or revising it critically for important intellectual content; and final approval of the version to be published; and agree to be accountable for all aspects of the work in ensuring that questions related to the accuracy or integrity of any part of the work are appropriately investigated and resolved. TS acts as guarantor.

Funding The SALIA follow-up study 2008 was funded by the German Statutory Accident Insurance (DGUV) Grant No: 617.0-FP266 and the European Community's Seventh Framework Programme (FP 7/2007-2011) under the grant agreement number 211250.

Competing interests Michael Abramson holds investigator initiated grants for unrelated research from Pfizer and Boehringer-Ingelheim. He has undertaken an unrelated consultancy for Sanofi and received a speaker's fee from GSK. The other authors have no competing interests to declare.
Patient and public involvement Patients and/or the public were not involved in the design, or conduct, or reporting, or dissemination plans of this research.

Patient consent for publication Not required.

Provenance and peer review Not commissioned; externally peer reviewed.

Data availability statement № data are available.

Open access This is an open access article distributed in accordance with the Creative Commons Attribution Non Commercial (CC BY-NC 4.0) license, which permits others to distribute, remix, adapt, build upon this work non-commercially, and license their derivative works on different terms, provided the original work is properly cited, appropriate credit is given, any changes made indicated, and the use is non-commercial. See: http://creativecommons.org/licenses/by-nc/4.0/.

ORCID iDs

Michael J Abramson http://orcid.org/0000-0002-9954-0538

Tamara Schikowski http://orcid.org/0000-0002-4559-9374

\section{REFERENCES}

1 Balakrishnan K, Dey S, Gupta T, et al. The impact of air pollution on deaths, disease burden, and life expectancy across the states of India: the global burden of disease study 2017. Lancet Planet Health 2019;3:e26-39.

2 Wang Q, Wang J, Zhou J, et al. Estimation of PM2-associated disease burden in China in 2020 and 2030 using population and air quality scenarios: a modelling study. Lancet Planet Health 2019;3:e71-80.

3 Doiron D, de Hoogh K, Probst-Hensch N, et al. Air pollution, lung function and COPD: results from the population-based UK Biobank study. Eur Respir J . 2019;54:1802140.

4 Roth GA, Abate D, Abate $\mathrm{KH}$, et al. Global, regional, and national age-sex-specific mortality for 282 causes of death in 195 countries and territories, 1980-2017: a systematic analysis for the global burden of disease study 2017. Lancet 2018;392:1736-88.

5 Toelle BG, Xuan W, Bird TE, et al. Respiratory symptoms and illness in older Australians: the burden of obstructive lung disease (BOLD) study. Med J Aust 2013;198:144-8.

6 Buist AS, McBurnie MA, Vollmer WM, et al. International variation in the prevalence of COPD (the BOLD study): a population-based prevalence study. Lancet . 2007;370:741-50.

7 Blanc PD, Annesi-Maesano I, Balmes JR, et al. The occupational burden of nonmalignant respiratory diseases. An official American thoracic Society and European respiratory Society statement. Am J Respir Crit Care Med 2019;199:1312-34.

8 Giroux M, Brémont F, Ferrières $\mathrm{J}$, et al. Exhaled NO in asthmatic children in unpolluted and urban environments. Environ Int 2001;27:335-40.

9 Smith AD, Taylor DR. Is exhaled nitric oxide measurement a useful clinical test in asthma? Curr Opin Allergy Clin Immunol 2005;5:49-56.

10 Dweik RA, Boggs PB, Erzurum SC, et al. An official ats clinical practice guideline: interpretation of exhaled nitric oxide levels (FENO) for clinical applications. Am J Respir Crit Care Med 2011;184:602-15.

11 Annesi-Maesano I, Dinh-Xuan AT. Is exhaled nitric oxide a marker of air pollution effect? Eur Respir J 2016;47:1304-6.

12 Schikowski T, Sugiri D, Ranft U, et al. Long-Term air pollution exposure and living close to busy roads are associated with COPD in women. Respir Res 2005;6:152.

13 Hüls A, Krämer U, Stolz S, et al. Applicability of the global lung initiative 2012 reference values for spirometry for longitudinal data of elderly women. PLoS One 2016;11:1-12.

14 Miller MR, Hankinson J, Brusasco V, et al. Standardisation of spirometry. Eur Respir J 2005;26:319-38.

15 Quanjer PH, Cole TJ, Hall GL, et al. Report of the global lung function initiative (Gli), ERS Task force to establish improved lung function reference values, including supplement. Eur Respir $J$ 2013;40:1324-43.

16 American Thoracic Society, European Respiratory SocietySilkoff P, Erzurum SC. ATS/ERS recommendations for standardized procedures for the online and offline measurement of exhaled lower respiratory nitric oxide and nasal nitric oxide, 2005. Am J Respir Crit Care Med 2005;171:912-30.

17 Eeftens M, Beelen R, de Hoogh K, et al. Development of land use regression models for PM2.5, PM 2.5 absorbance, PM10 and PMcoarse in 20 European study areas; Results of the ESCAPE project. Environ Sci Technol 2012;46:11195-205.

18 Beelen R, Hoek G, Vienneau D, et al. Development of NO2 and Nox land use regression models for estimating air pollution exposure 
in 36 study areas in Europe - the ESCAPE project. Atmos Environ 2013;72:10-23.

19 Nerpin E, Olivieri M, Gislason T, et al. Determinants of fractional exhaled nitric oxide in healthy men and women from the European Community Respiratory Health Survey III. Clin Exp Allergy 2019:49:969-79.

20 Krzyzanowski M, Cohen A. Update of who air quality guidelines. Air Qual Atmos Health 2008:1:7-13.

$21 \mathrm{Wu} \mathrm{S}$, Ni Y, Li H, et al. Short-Term exposure to high ambient air pollution increases airway inflammation and respiratory symptoms in chronic obstructive pulmonary disease patients in Beijing, China. Environ Int 2016;94:76-82.

22 Li H, Wu S, Pan L, et al. Short-Term effects of various ozone metrics on cardiopulmonary function in chronic obstructive pulmonary disease patients: results from a panel study in Beijing, China. Environ Pollut 2018;232:358-66.

23 Dales R, Wheeler A, Mahmud M, et al. The influence of living near roadways on spirometry and exhaled nitric oxide in elementary schoolchildren. Environ Health Perspect 2008;116:1423-7.

24 Cakmak S, Mahmud M, Grgicak-Mannion A, et al. The influence of neighborhood traffic density on the respiratory health of elementary schoolchildren. Environ Int 2012;39:128-32.

25 Berhane K, Zhang Y, Linn WS, et al. The effect of ambient air pollution on exhaled nitric oxide in the children's health study. Eur Respir J 2011;37:1029-36.

26 Eckel SP, Berhane K, Salam MT, et al. Residential traffic-related pollution exposures and exhaled nitric oxide in the children's health study. Environ Health Perspect 2011;119:1472-7.

27 Knibbs LD, Cortés de Waterman AM, Toelle BG, et al. The Australian child health and air pollution study (ACHAPS): a national populationbased cross-sectional study of long-term exposure to outdoor air pollution, asthma, and lung function. Environ Int 2018;120:394-403.
28 Eckel SP, Zhang Z, Habre R, et al. Traffic-Related air pollution and alveolar nitric oxide in southern California children. Eur Respir $J$ 2016;47:1348-56.

29 Riddervold I, Bønløkke J, Olin A-C, et al. Effects of wood smoke particles from wood-burning stoves on the respiratory health of atopic humans. Part Fibre Toxicol 2012;9:12.

30 Mirabelli MC, Golan R, Greenwald R, et al. Modification of trafficrelated respiratory response by asthma control in a population of car Commuters. Epidemiology 2015;26:546-55.

31 Zhang J, Zhu T, Kipen H, et al. Cardiorespiratory biomarker responses in healthy young adults to drastic air quality changes surrounding the 2008 Beijing Olympics. Res Rep Health Eff Inst 2013;174:5-174.

32 Modig L, Dahgam S, Olsson D, et al. Short-Term exposure to ozone and levels of exhaled nitric oxide. Epidemiology 2014;25:79-87.

33 Thiering E, Heinrich J. Epidemiology of air pollution and diabetes. Trends Endocrinol Metab 2015;26:384-94.

34 Peng C, Luttmann-Gibson $\mathrm{H}$, Zanobetti A, et al. Air pollution influences on exhaled nitric oxide among people with type II diabetes. Air Qual Atmos Health 2016;9:265-73.

35 Rao X, Zhong J, Brook RD, et al. Effect of particulate matter air pollution on cardiovascular oxidative stress pathways. Antioxid Redox Signal 2018;28:797-818.

36 Upadhyay S, Ganguly K, Stoeger T, et al. Cardiovascular and inflammatory effects of intratracheally instilled ambient dust from Augsburg, Germany, in spontaneously hypertensive rats (SHRs). Part Fibre Toxicol 2010;7:27-20.

37 Maniscalco M, Vitale C, Vatrella A, et al. Fractional exhaled nitric oxide-measuring devices: technology update. MDER 2016;9:151-60.

38 R Core Team. R: a language and environment for statistical computing. Vienna, Austria: R Foundation for Statistical Computing, 2019. https://www.r-project.org/ 